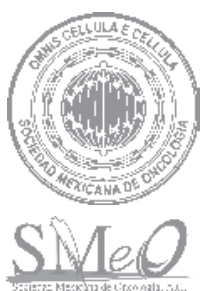

SOCIEDAD MEXICANA DE ONCOLOGÍA, A.C

CLINICAL CASE

\title{
Incidentally-Diagnosed Multiple Endocrine Neoplasia IIA (Sipple Syndrome) with Bilateral Pheochromocytoma and Medullary Thyroid Carcinoma
}

\author{
Vera Eunice Robles-Pérez ${ }^{1, *}$, Jeannette Liliana Córdova-López², Carlos Alejandro \\ Hernández-González ${ }^{3}$, Jorge Alberto Medina-Medina ${ }^{4}$, Víctor Hugo Ramos-Cano ${ }^{5}$ \\ and Eurídice Robles-Pérez ${ }^{6}$
}

${ }^{1}$ Department of Surgical Oncology, Hospital Regional $1^{\circ}$ de Octubre, ISSSTE; ${ }^{2}$ Department of Pediatric Cardiology, Hospital Pediátrico de Azcapotzalco, SS CDMX; ${ }^{3}$ Department of Pathology and ${ }^{4}$ Department of General Surgery, Hospital Regional $1{ }^{\circ}$ de Octubre, ISSSTE; ${ }^{5}$ Department of Cardiovascular Surgery and ${ }^{6}$ Department of Thoracic Surgery, Hospital Juárez de México, SS; Mexico City, Mexico

Received for publication: 7 January 2017; accepted for publication: 25 February 2017 Available online: 14 July 2017

\section{KEYWORDS}

Multiple endocrine neoplasia IIA; Medullary thyroid carcinoma; Pheochromocytoma; RET proto-oncogene

\begin{abstract}
Multiple endocrine neoplasia IIA, also known as Sipple syndrome, is a rare entity that is difficult to diagnose and potentially fatal and is caused by RET proto-oncogene mutations. The importance of its diagnosis and determination of this mutation in the patient and his/her consanguineous relatives lies in avoiding the appearance of medullary thyroid cancer by means of prophylactic thyroidectomy and follow-up at the appearance of pheochromocytoma or parathyroid adenoma. We present the case of a female asymptomatic patient with the TGC34AGC-Cys634Arg mutation who was diagnosed with medullary thyroid carcinoma and bilateral pheochromocytoma, had a family history of thyroid and adrenal tumor-related deaths, was treated for curative purposes, and in whom the diagnosis was suspected by screening studies. (creativecommons.org/licenses/by-nc-nd/4.0/).
\end{abstract}

*E-mail for correspondence: roblesvera@yahoo.com (V.E. Robles-Pérez) 


\section{INTRODUCTION}

Sipple syndrome, an eponym used to designate multiple endocrine neoplasia type IIA (OMIM \#171400) ${ }^{1}$, is a rare and potentially fatal disease that affects one in every 40,000 people. It is an autosomal recessive condition, the clinical spectrum of which includes the presence of pheochromocytoma, medullary thyroid carcinoma, and parathyroid adenomas ${ }^{2}$.

The description of this disease dates back to 1961 when Dr. John H. Sipple presented a series of 537 cases of pheochromocytoma, out of which five were strongly associated with thyroid gland carcinoma ${ }^{3}$. Subsequently, in 1965, Schimke demonstrated the association of pheochromocytoma with medullary thyroid carcinoma ${ }^{4}$. Finally, both these conditions and the presence of parathyroid adenomas have distinguished this entity.

Clinical diagnosis is rarely suspected and it occurs mostly during study protocols of patients who may display: (i) high blood pressure secondary to a pheochromocytoma, (ii) hypercalcemia in the causative study of pyeloureteral lithiasis, or (iii) during the screening of a thyroid nodule that results in medullary cancer when there is a family history of this type of neoplasm. However, many times the syndrome goes unnoticed and the patient dies without a diagnosis, which puts the family integrity at risk since transmission of the disease occurs in up to $50 \%$ of the offspring. If, on the other hand, we consider that the diagnosis of this syndrome forces to consider prophylactic thyroidectomy at ages as early as five years, given that these patients will develop medullary thyroid cancer in up to $95 \%$ of cases, we can consider Sipple syndrome to be a highly important entity.

Since 1998, the RET proto-oncogene has been associated with medullary thyroid carcinoma as a result of studies carried out by Shirahama, et al. ${ }^{5}$. In 2000, the molecular mechanisms likely involved in the development of tumors by mutations in this proto-oncogene were discovered by Huang, et al. $^{6}$ and Koch, et al. ${ }^{7}$. Currently, the cause of Sipple syndrome is accepted to be a mutation in the RET proto-oncogene, which encodes for a tyrosine kinase receptor located in chromosome 10q11.21. There are 52 documented allelic variants $^{8}$, with 17 of them being involved with the development of Sipple syndrome. From $73-85 \%$ are found at codon 634 in exon 11 (C634R and C634Y) and 10-20\% at codons 609, 611, 618, and 620 in exon 10.

Molecular diagnosis of this syndrome can be carried out by demonstrating RET gene mutations, which is the gold standard; however, the diagnosis can also be established with the demonstration of two neoplasias in a single individual or in a first-degree relative. If a genetic study is not feasible, this should not delay diagnosis and treatment ${ }^{9,10}$.

Wells, et al. ${ }^{11}$ demonstrated that total thyroidectomy in asymptomatic patients with proto-oncogene RET mutations can prevent or cure medullary thyroid carcinoma, which is a neoplasm with multifocal, bilateral presentation that spreads early to the lymph nodes. Currently, there are protocols that justify this surgery in certain types of RET mutations ${ }^{12-14}$.

This syndrome is regularly accompanied by pheochromocytoma and parathyroid adenoma. Other characteristics that may be included are Hirschsprung's disease and Cushing syndrome ${ }^{15}$.
We present the case of an asymptomatic female patient diagnosed with Sipple syndrome (multiple endocrine neoplasia IIA) with medullary thyroid carcinoma and bilateral pheochromocytoma who had a family history of thyroid- and adrenal tumor-associated deaths and was treated for curative purposes.

\section{CLINICAL CASE}

This is the case of a 50-year-old female patient with a family history of thyroid tumors in her great-grandmother, grand father, aunt, and mother, all of them by the maternal line (Figs. 1-6 and Table 1), who had lactate dehydrogenase and aspartate and alanine aminotransferase elevations in a routine yearly checkup, which prompted for a liver ultrasound to be performed where lesions were detected in the hepato- and splenorenal spaces. Liver triphasic CT scan showed tumors dependent on both adrenal glands. In addition, metanephrine plasma levels were elevated. Finally, a metaiodobenzylguanidine- ${ }^{131}$ uptake study was performed, which generated sufficient evidence to consider the bilateral pheochromocytoma diagnosis, with surgery being indicated.

Preoperatively, alpha-adrenergic receptor blockage was applied, followed by beta blockage for surgical extirpation by the laparoscopic route, which was carried out with no accidents or incidents and with right and left tumors being found of 3 and $5 \mathrm{~cm}$ at the longest diameter, respectively. The histopathological analysis result indicated bilateral phe=ochromocytoma.

Although the CT scan, the bone scintigraphy, and the metaiodobenzylguanidine-| ${ }^{131}$ uptake study allowed for the presence of catecholamine-producing tissue other than that found in the adrenal glands to be ruled out, these tests, together with serum calcium and calcitonin elevated levels, allowed for a lesion in the thyroid gland right lobe to be detected; thyroid gland function tests were normal.

Following the protocol, a neck CT scan was performed where bilateral thyroid nodules and right-side neck adeno-o megalies were found, which warranted an ultrasound-guided fine-needle aspiration biopsy that turned out to be highly suspicious of malignancy.

Owing to these findings, the patient underwent total thyroidectomy and type III right-side neck and central compartment radical resection, with the surgery encompassing two parathyroid glands' excision. The histopathology result showed bilateral medullary thyroid carcinoma with metas tasis to right-side lymph nodes and two parathyroid glands with no alterations. With these findings, the Sipple syndrome diagnosis was established and the case was referred to genetic counseling with the purpose to include the family in a protocol in order to determine the performance of prophylactic thyroidectomy.

The sequencing studies for the RET gene showed a thymine-adenine heterozygous mutation at the 634 position (TGC634AGC $\rightarrow$ Cys634Arg).

Currently, the patient is asymptomatic on thyroid-replacement therapy, steroid supplementation, and thyroid pathology management. Calcitonin levels are currently at $137 \mathrm{pg} / \mathrm{ml}$, and genetic sequencing studies will be carried out in her consanguineous relatives. 


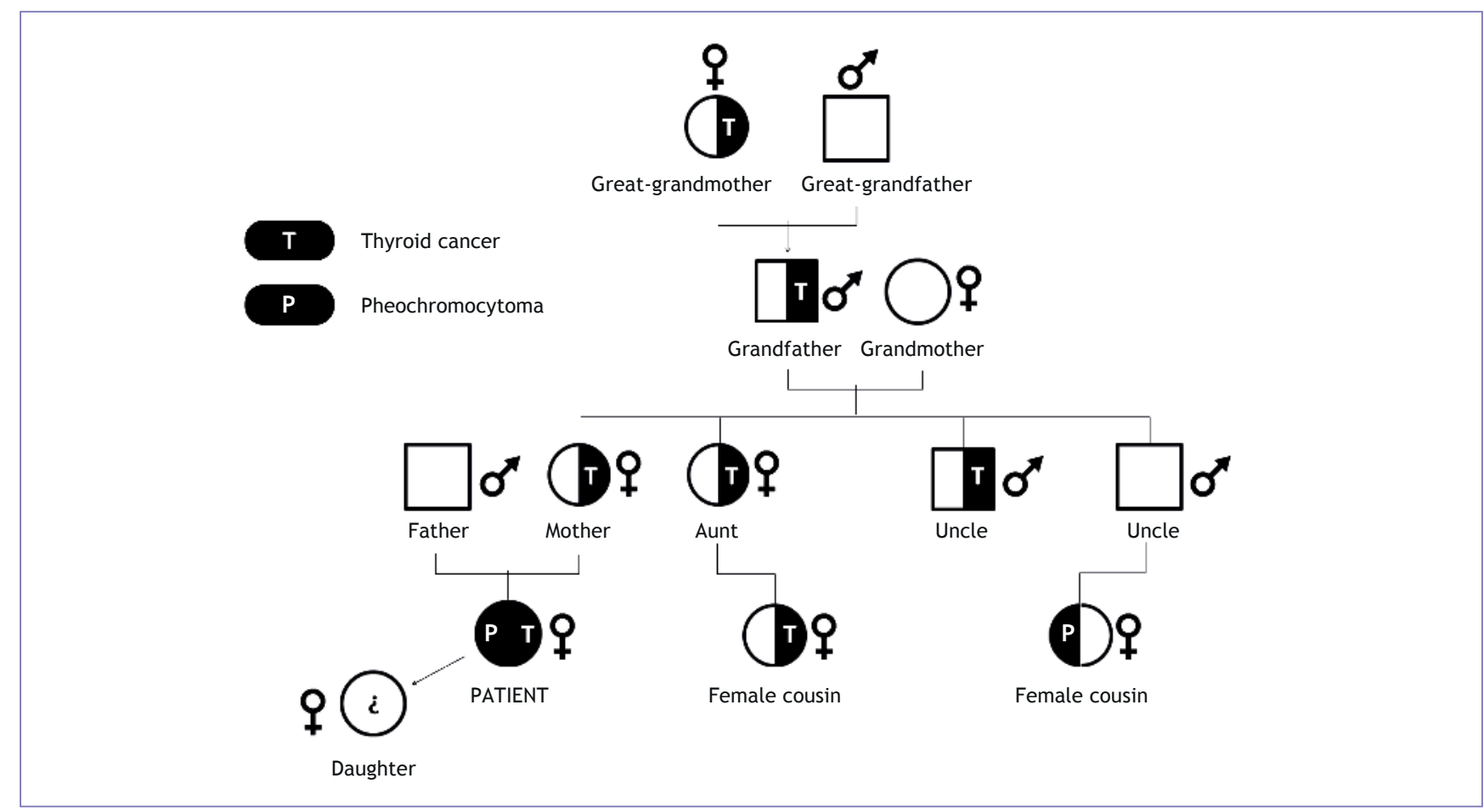

Figure 1. Family tree showing the recurrence of pheochromocytoma and medullary thyroid cancer.

\section{DISCUSSION}

Sipple syndrome or multiple endocrine neoplasia type IIA is a rare condition that commonly produces initial clinical signs and symptoms that mostly can be grouped into four types of presentation:

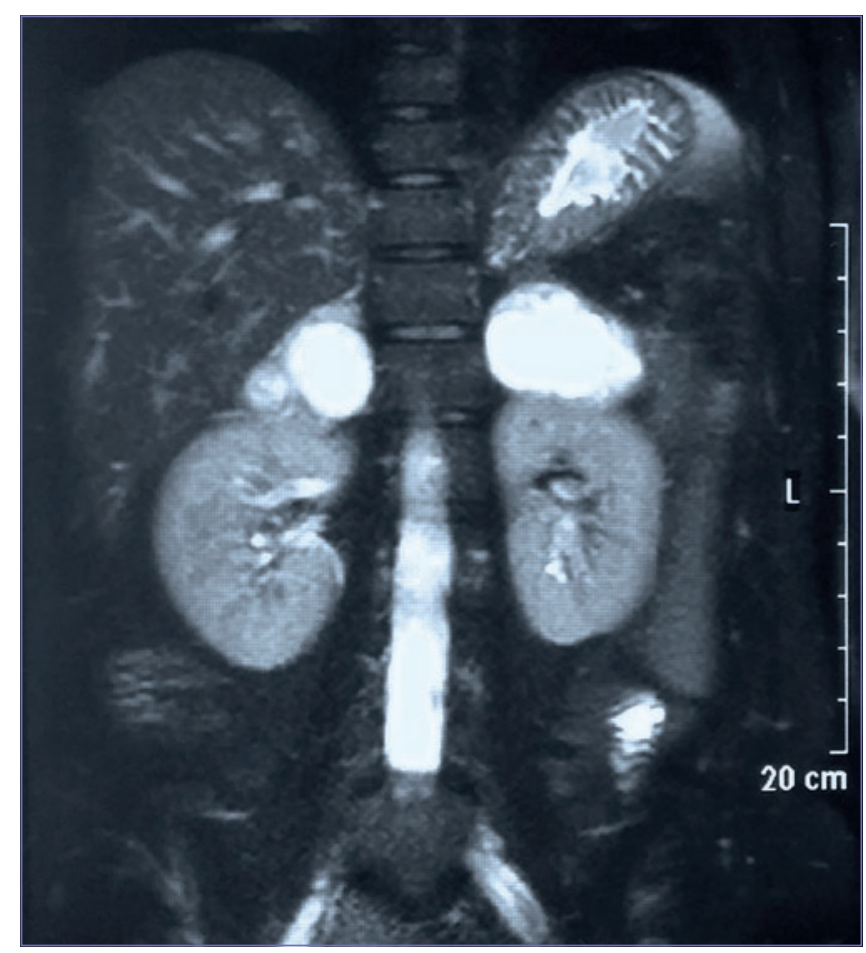

Figure 2. Magnetic resonance imaging revealing bilateral adrenal tumors.
The first one corresponds to those symptoms resulting from blood-circulating catecholamine level increase owing to functioning tumors deriving from chromaffin cell prolif eration. Patients initially experience headache, sweating, tachycardia, nervousness and irritability, weight loss, and sometimes abdominal or chest pain. Many of them are diag

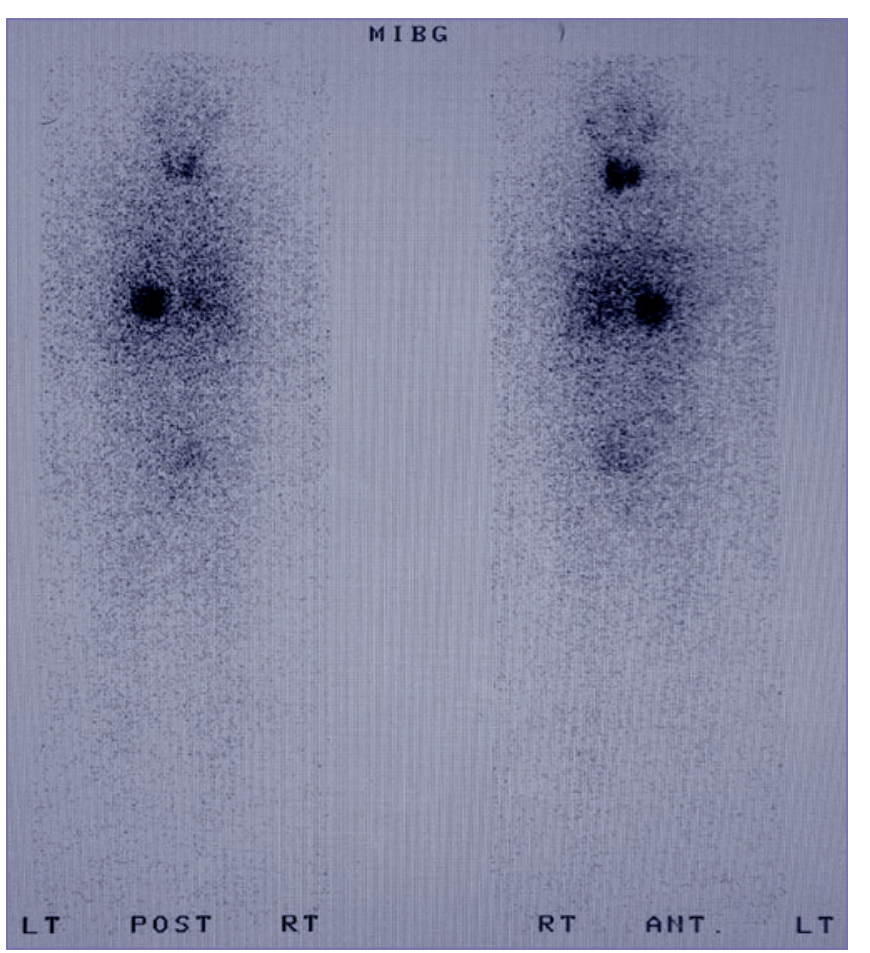

Figure 3. Scintigraphy with metaiodobenzylguanidine-| ${ }^{131}$ showing bilateral adrenal region and thyroid uptake. 


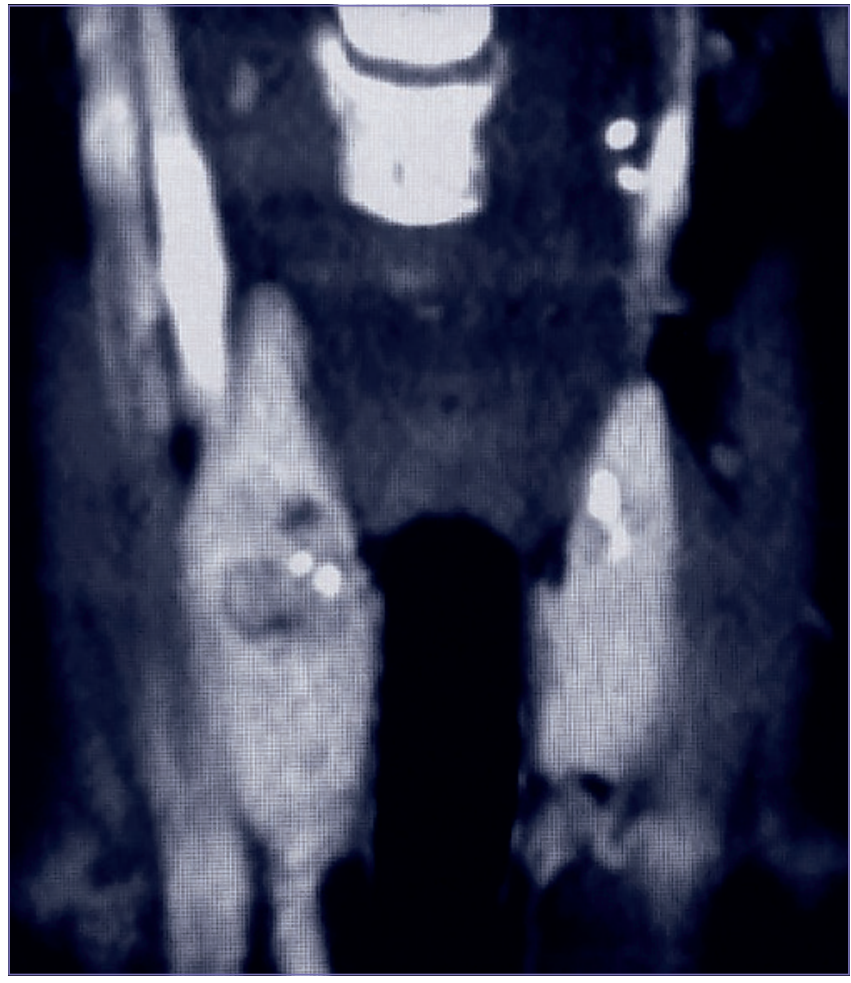

Figure 4. Neck CT-scan revealing heterogeneous, vascularized nodule on right thyroid lobe, as well as bilateral calcifications.

nosed with high blood pressure and cases are not rare where symptoms may be confused with panic attacks, generalized anxiety disorder, or other similar conditions that ultimately are later diagnosed as pheochromocytomas ${ }^{16}$, and in the case of this syndrome, sometimes when patients have already developed medullary thyroid cancer.

A second spectrum corresponds to asymptomatic patients who accidentally feel a cervical growth or palpate one or several lymph nodes that grow in number and size over time and where a thyroid nodule is identified, which after the corresponding protocol is diagnosed as medullary thyroid cancer $^{17}$.

The third type of manifestation corresponds to those patients with generalized joint pain, abdominal pain, depression, or urolithiasis, where the protocol reveals the presence of hypercalcemia, which drives to the suspicion of hyperparathyroidism and parathyroid adenoma ${ }^{18}$.

Finally, there is a type of patients in whom one or more of the main Sipple syndrome components indirectly develop manifestations that direct the diagnostic protocol towards other entities such as peptic ulcer ${ }^{19}$, cutaneous lichen am yloidosis ${ }^{20}$, Cushing syndrome ${ }^{21}$, and catecholamine-induced cardiomyopathy ${ }^{22}$; even thyroidectomy for causes other than medullary thyroid cancer has been reported to yield parafollicular cell hyperplasia as a result, which raises suspicion and subsequently leads to diagnosis ${ }^{23}$. There is even one case reported by Casey, et al. ${ }^{24}$, who decided to implement a diagnostic protocol in a 35-year-old female patient with fatigue and weight loss, and discovered hepatic masses that turned out to be medullary thyroid cancer metastases, which differentiates this case from ours where no distant metastasis was demonstrated. However, no entirely asymptomatic case has been yet reported in the literature.

The presence of bilateral pheochromocytoma and medul: lary thyroid cancer at diagnosis is infrequent, but it is neces sary, by itself, for the type IIA multiple endocrine neoplasia diagnosis to be integrated, and this is the reason why the pheochromocytomas were excised and total thyroidectomy was practiced.

In the presence of a medullary thyroid cancer index case, familial genetic study is indispensable. Prophylactic thyroidectomy is the only curative treatment, with it being dependent on the mutation type ${ }^{25,26}$. Since the coincidence of presence of the disease and the mutation-carrier status is higher than $95 \%$, the study has to be also performed in consanguineous relatives.
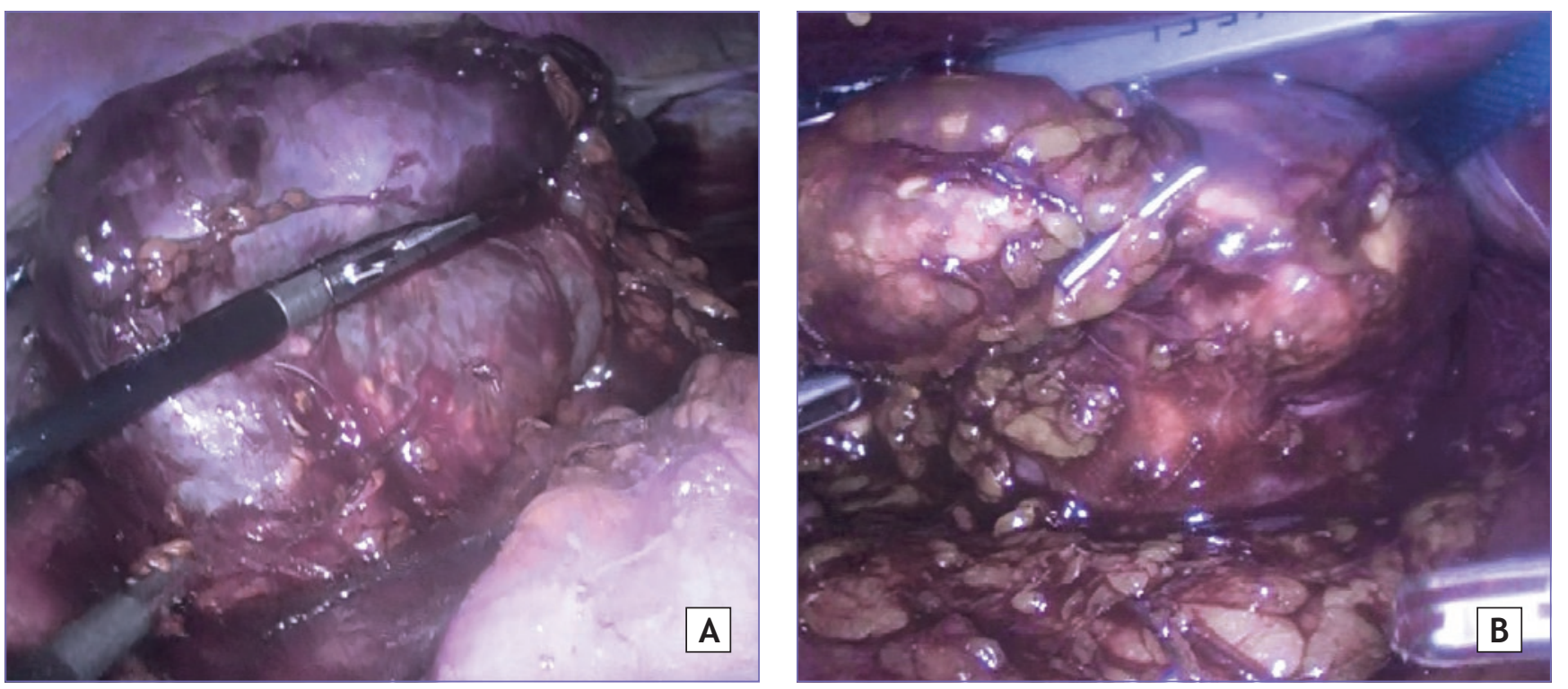

Figure 5. Left (A) and right (B) adrenalectomy. 
Table 1. Baseline and end-of-treatment laboratory tests

\begin{tabular}{|c|c|c|c|}
\hline & Baseline & $\begin{array}{c}\text { Final } \\
\text { (after surgeries) }\end{array}$ & $\begin{array}{l}\text { Reference } \\
\text { values }\end{array}$ \\
\hline Alanine aminotransferase & $234 \mathrm{IU} / \mathrm{l}$ & $29 \mathrm{IU} / \mathrm{l}$ & $10-40 \mathrm{IU} / \mathrm{l}$ \\
\hline Aspartate aminotransferase & $154 \mathrm{IU} / \mathrm{I}$ & $23 \mathrm{IU} / \mathrm{I}$ & $10-42 \mathrm{IU} / \mathrm{l}$ \\
\hline Lactate dehydrogenase & $259 \mathrm{IU} / \mathrm{l}$ & $196 \mathrm{IU} / \mathrm{I}$ & $0-248 \mathrm{IU} / \mathrm{I}$ \\
\hline \multicolumn{4}{|l|}{ Urinary metanephrines } \\
\hline Total metanephrines & $1609.49 \mu \mathrm{g} / 24 \mathrm{~h}$ & $204 \mu \mathrm{g} / 24 \mathrm{~h}$ & $<900 \mu \mathrm{g} / 24 \mathrm{~h}$ \\
\hline Urinary metanephrines & $638.60 \mu \mathrm{g} / 24 \mathrm{~h}$ & $74 \mu \mathrm{g} / 24 \mathrm{~h}$ & $<350 \mu \mathrm{g} / 24 \mathrm{~h}$ \\
\hline Normetanephrines & $970.89 \mu g / 24 \mathrm{~h}$ & $130 \mu \mathrm{g} / 24 \mathrm{~h}$ & $<600 \mu \mathrm{g} / 24 \mathrm{~h}$ \\
\hline Noradrenaline & $109.2 \mu \mathrm{g} / 24 \mathrm{~h}$ & $80 \mu \mathrm{g} / 24 \mathrm{~h}$ & $0-90 \mu \mathrm{g} / 24 \mathrm{~h}$ \\
\hline Adrenaline & $27 \mu \mathrm{g} / 24 \mathrm{~h}$ & $23 \mu \mathrm{g} / 24 \mathrm{~h}$ & $0-20 \mu \mathrm{g} / 24 \mathrm{~h}$ \\
\hline Dopamine & $1,050.59 \mu \mathrm{g} / 24 \mathrm{~h}$ & $115 \mu \mathrm{g} / 24 \mathrm{~h}$ & $0-600 \mu \mathrm{g} / 24 \mathrm{~h}$ \\
\hline Plasma metanephrines & $93.46 \mathrm{pg} / \mathrm{ml}$ & $40 \mathrm{pg} / \mathrm{ml}$ & $<90 \mathrm{pg} / \mathrm{ml}$ \\
\hline Plasma free metanephrines & $83.0 \mathrm{pg} / \mathrm{ml}$ & $56 \mathrm{pg} / \mathrm{ml}$ & $0-62 \mathrm{pg} / \mathrm{ml}$ \\
\hline Plasma free normetanephrines & $445 \mathrm{pg} / \mathrm{ml}$ & $120 \mathrm{pg} / \mathrm{ml}$ & $0-145 \mathrm{pg} / \mathrm{ml}$ \\
\hline Calcitonin & $4,010 \mathrm{pg} / \mathrm{ml}$ & $137 \mathrm{pg} / \mathrm{ml}$ & $0-11.5 \mathrm{pg} / \mathrm{ml}$ \\
\hline \multicolumn{4}{|l|}{ Thyroid function tests } \\
\hline TSH & $1.68 \mu \mathrm{lU} / \mathrm{ml}$ & $0.02 \mu \mathrm{lU} / \mathrm{ml}$ & $0.30-4.67 \mu \mathrm{lU} / \mathrm{ml}$ \\
\hline Total T3 & $0.96 \mathrm{ng} / \mathrm{ml}$ & $0.86 \mathrm{ng} / \mathrm{ml}$ & $0.76-2.2 \mathrm{ng} / \mathrm{ml}$ \\
\hline Total T4 & $8.26 \mu \mathrm{g} / \mathrm{dl}$ & $13.20 \mu \mathrm{g} / \mathrm{dl}$ & $4.5-12.60 \mu \mathrm{g} / \mathrm{dl}$ \\
\hline Free T4 & $1.30 \mathrm{ng} / \mathrm{dl}$ & $2.51 \mathrm{ng} / \mathrm{dl}$ & $0.71-1.85 \mathrm{ng} / \mathrm{dl}$ \\
\hline
\end{tabular}

\section{CONCLUSION}

Sipple syndrome is rare disease with different presentations. It is potentially lethal and its opportune diagnosis has consequences not only for the patient's life but also for that of his/her relatives since this is an autosomal-dominant familial syndrome.

In most cases, the diagnosis is based on suspicion or is established by the presence of pheochromocytoma, medullary thyroid carcinoma, and/or parathyroid adenoma, even more so if any of these conditions is recurrent in the family.

Even when it is the gold standard, the demonstration of a specific mutation in the RET proto-oncogene should not delay the diagnosis and treatment of the disease in patients in whom it cannot be carried out.

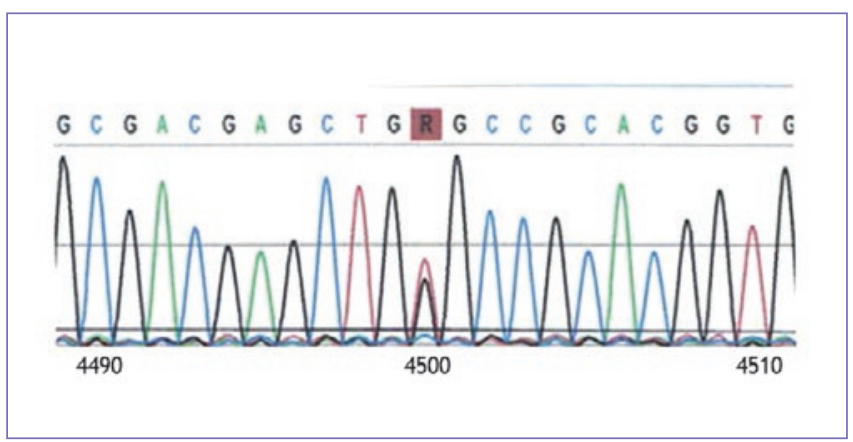

Figure 6. Electrophoretogram showing thymine-adenine heterozygous mutation at the 634 position (TGC634AGC - Cys634Arg).

\section{DECLARATION OF INTEREST}

The authors declare not having any social, economic, ethical and/or moral conflict of interest with regard to the investigation, development, and presentation of this work.

\section{REFERENCES}

1. Omim.org. (2017). OMIM Entry - \# 171400 - MULTIPLE ENDOCRINE NEO= PLASIA, TYPE IIA; MEN2A. Available at: http://omim.org/entry/171400 (Accessed 22 Jan. 2017).

2. Marquard J, Eng C. Multiple Endocrine Neoplasia Type 2. 1999 Sep 27 [Updated 2015 Jun 25]. In: Pagon RA, Adam MP, Ardinger HH, et al. editors. GeneReviews ${ }^{\oplus}$ [Internet]. Seattle (WA): University of Washing-o ton, Seattle; 1993-2017. Available at: https://www.ncbi.nlm.nih.goy/ books/NBK1257/ (Accessed 22 Jan. 2017).

3. Sipple J. The association of pheochromocytoma with carcinoma of the thyroid gland. Am J Med. 1961;31:163-6.

4. Schimke, R. Familial amyloid-producing medullary thyroid carcinoma and pheochromocytoma. Ann Intern Med. 1965;63:1027-39.

5. Shirahama S, Ogura K, Takami H, et al. Mutational analysis of the RET proto-oncogene in 71 Japanese patients with medullary thyroid carcinoma. J Hum Genet. 1998;43:101-6.

6. Huang SC, Koch CA, Vortmeyer AO, et al. Duplication of the mutant RET allele in trisomy 10 or loss of the wild-type allele in multiple endocrine neoplasia type 2-associated pheochromocytomas. Cancer Res. 2000;60:6223-6.

7. Koch C, Huang SC, Moley JF, et al. Allelic imbalance of the mutant and wild-type RET allele in MEN 2A-associated medullary thyroid carcinoma. Oncogene. 2001;20:7809-11.

8. Omim.org. (2017). OMIM RET Allelic Variants - 164761. Available at: http://omim.org/allelicVariant/164761 (Accessed 22 Jan. 2017).

9. Kloos RT, Eng C, Evans DB, et al. American Thyroid Association Guidelines Task Force. Medullary Thyroid Cancer: Management Guidelines of the American Thyroid Association. Thyroid. 2009;19:565-612. 
10. Moline J, Eng C. Multiple endocrine neoplasia type 2: An overview. Genet Med. 2011;13:755-64.

11. Wells SA, Chi DD, Toshima K, et al. Predictive DNA testing and prophylactic thyroidectomy in patients at risk for multiple endocrine neoplasia type 2A. Ann Surg. 1994;220:237-50.

12. Skinner M, Moley JA, Dilley WG, Owzar K, Debenedetti MK, Wells SA, et al. Prophylactic thyroidectomy in multiple endocrine neoplasia Type 2A. N Engl J Med. 2005;353:1105-13.

13. Fahey T. Prophylactic thyroidectomy in multiple endocrine neoplasia type 2A. Yearbook of Surgery. 2006;144.

14. Glynn RW, Cashman EC, Doody J, Phelan E, Russell JD, Timon C. et al. Prophylactic total thyroidectomy using the minimally invasive video-assisted approach in children with multiple endocrine neoplasia type 2 . Head Neck. 2014;36:768-71.

15. Opsahl EM, Brauckhoff $M$, Schlichting $E$, et al. A nationwide study of multiple endocrine neoplasia type $2 \mathrm{~A}$ in Norway: predictive and prognostic factors for the clinical course of medullary thyroid carcinoma. Thyroid. 2016;26:1225-38.

16. Tsang V, Tacon L, Learoyd D, Robinson B. Pheochromocytomas in multiple endocrine neoplasia Type 2. Recent Results Cancer Res. 2015;204:157-78.

17. Morlán Herrador L, de Arriba A, Miguel G, Ferrera M, Labarta JI. [Study of medullary thyroid carcinoma from a proband]. Arch Argent Pediatr. 2016;114:e421-4.
18. Alevizaki M. Saltiki K. Primary hyperparathyroidism in MEN2 syndromes. Recent Results Cancer Res. 2015;204:179-86.

19. Weledji E. A rare presentation of multiple endocrine neoplasia (MEN) type 2A syndrome. Ann Med Surg. 2016;5:35-7.

20. Birla S, Singla R, Sharma A, Tandon N. Rare manifestation of multiple endocrine neoplasia type 2A \& cutaneous lichen amyloidosis in a family with RET gene mutation. Indian J Med Res. 2014;139:779-81.

21. Borzouei S, Mousavi Bahar SH, Fereydouni MA, Salimbahrami SA, Taghipour M. Multiple endocrine neoplasia type Ila associated with Cushing's syndrome. Arch Iran Med. 2014;17:451-4.

22. Gómez RM, Gonzáez VF, Sánchez AM. Sipple's syndrome presenting acutely as severe heart failure. Eur J Emerg Med. 2002;9:171-4.

23. Sakorafas G, Nasikas D, Thanos D, Gantzoulas S. Incidental thyroid $\mathcal{C}$ cell hyperplasia: clinical significance and implications in practice? Oncol Res Treat. 2015;38:249-52.

24. Casey R, Bell M, Keane M, Smyth A. An unusual presentation of MEN2A. BMJ Case Rep. 2013;2013.

25. Krampitz G, Norton J. RET gene mutations (genotype and phenotype) of multiple endocrine neoplasia type 2 and familial medullary thyroid carcinoma. Cancer. 2014;120:1920-31.

26. Wells SA, Asa SL, Dralle H, et al. American Thyroid Association Guidelines Task Force on Medullary Thyroid Carcinoma. Revised American Thyroid Association Guidelines for the Management of Medullary Thyroid Carcinoma. Thyroid. 2015;25:567-610. 